\title{
Editorial
}

J. Appl. Cryst. (1993). 26, 468

\section{Computer Programs for CIF Applications}

The Crystallographic Information File (CIF) is now the recommended format for submitting data and other material for publication in Acta Crystallographica Section C. Since the announcement by the International Union of Crystallography that it has adopted the CIF format for its archiving and publication activities [Hall, Allen \& Brown (1991). Acta Cryst. A47, 655-685], there has been a considerable effort to develop computer software for the generation and reading of CIF data. The availability of these programs has been a determining factor in the rapid adoption of the CIF approach to publication of structural data.
The four program descriptions that follow are the first papers of what is intended to be a series on CIF software applications. Authors of any software that reads, writes or validates CIF data are invited to contribute to this series. Authors should state clearly when submitting a manuscript to a Co-editor of J. Appl. Cryst. that the paper should be included as part of the 'CIF Applications' series. An appropriate series number will be assigned by the technical-editing staff.

A. M. GLAZER

Editor, Journal of Applied Crystallography 